\title{
Electrophysiological features of complete AV block within the His bundle
}

\author{
Prem K. Gupta, Edgar Lichstein, and Kul Chadda \\ From the Department of Medicine, Division of Cardiology, Mount Sinai Hospital Services, City Hospital \\ Center at Elmhurst, Mount Sinai School of Medicine of the City University of New York, N.Y., U.S.A.
}

The site of block in 3 patients with complete heart block was localized within the His bundle with the aid of the His bundle electrogram. Two patients had normal QRS morphology while the third had a pattern of right bundle-branch block. Split His bundle potentials, i.e. $H$ and $H^{\prime}$ denoting the activity of the proximal and distal His bundle segments, were seen in all 3 patients. Atrial pacing in 2 patients produced a gradual increase in the $A H$ interval, consistent with normal $A V$ nodal function. In one of these, His bundle pacing was also successful and produced QRS complexes similar to the spontaneous beats. Intravenous atropine was used in 2 patients. In one it did not increase the heart rate, while in the other the heart rate increased slightly. It is concluded that heart block may occur within the main His bundle and that the surface electrocardiogram is of no use in predicting the site of block in such patients. Response to intravenous atropine may be inadequate or absent.

The technique of His bundle electrography introduced by Scherlag et al. (1969) has made possible the localization of the site of delay in various atrioventricular conduction abnormalities. Block occurring within the His bundle was initially described by Narula and Samet (1970). Two types of His bundle potentials, i.e. $\mathrm{H}$ and $\mathrm{H}^{\prime}$ denoting the activity of the proximal and distal His bundle segments, were recorded in such patients. More recently, several other workers have described patients with various conduction abnormalities localized within the His bundle (Gupta et al., 1972a; Rosen et al., 1971, 1972; Schuilenberg and Durrer, 1972). The present report describes three cases of complete AV block within the His bundle. The results of $\mathrm{His}$ bundle pacing and the response to atropine are discussed.

\section{Electrophysiological studies}

The His bundle electrograms were recorded by the method described by Scherlag et al. (1969). A size 6, bipolar electrode wire with interelectrode distance of I cm was passed percutaneously via the right femoral vein and advanced to the tricuspid valve. Electrograms were recorded on an Electronics for Medicine ${ }^{1}$ multichannel recorder at a frequency response of $40-500 \mathrm{~Hz}$ and paper speeds of 75 and $150 \mathrm{~mm} / \mathrm{sec}$. One or more

Received 17 November 1972.

${ }^{1}$ Electronics for Medicine, Inc., White Plains, New York. leads of the peripheral electrocardiogram were recorded simultaneously. Atrial pacing was performed by a second bipolar wire which was positioned against the lateral wall of the right atrium.

The following measurements were made. The AH interval which included AV nodal conduction time was measured from the onset of the atrial depolarization (A) to the onset of the proximal His bundle deflection $(\mathrm{H})$. The $H^{\prime} Q$ interval which represents conduction time in the distal His bundle segment and bundle-branches was measured from the onset of the distal His bundle deflection $\left(\mathrm{H}^{\prime}\right)$ to the onset of the ventricular depolarization.

\section{Case reports}

Case I A 74-year-old Cuban-born woman was seen at the cardiac clinic because of episodes of dizziness of several months' duration. Six months before this visit, the patient was noted to have a slow pulse rate by her physician. Physical examination revealed a regular pulse rate of 39 a minute. Blood pressure was $190 / 90 \mathrm{mmHg}$ in both arms. A I2-lead electrocardiogram on admission (Fig. I) showed complete AV block with an atrial rate of 93 a minute and a ventricular rate of 39 a minute. The ventricular complexes were narrow and measured $0.08 \mathrm{sec}$ in duration. The His bundle electrograms were recorded during temporary pacemaker insertion. Fig. 2 shows the His bundle electrograms of this patient with a lead II electrocardiogram. Complete AV block is evident. Each atrial depolarization $(\mathrm{A})$ is followed by a biphasic proximal His bundle potential $(\mathrm{H})$ at an $\mathrm{AH}$ interval of $95 \mathrm{msec}$. Every ventricular depolarization is preceded by a separate biphasic spike labelled $\mathrm{H}^{\prime}$ at an 


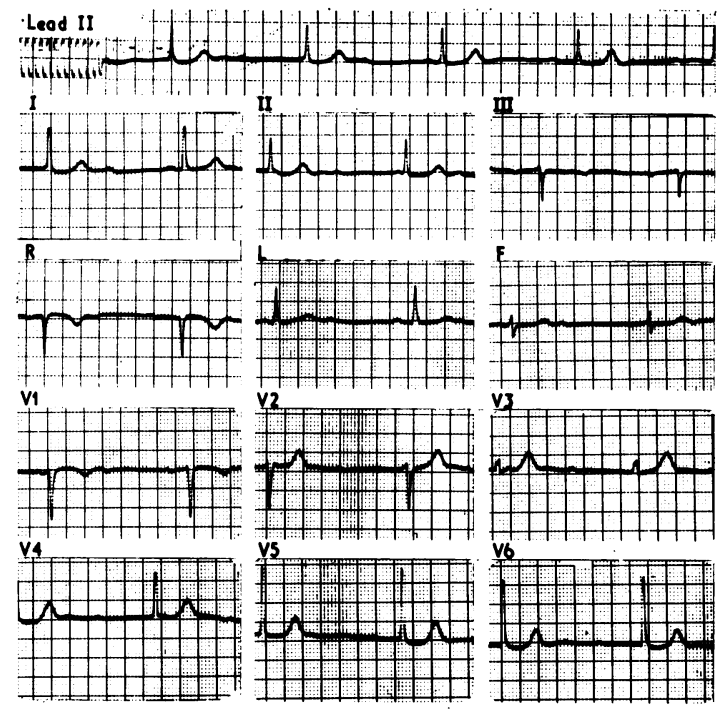

FIG. I Case I. A I2-lead electrocardiogram showing complete heart block with narrow supraventricular $Q R S$ complexes.

$\mathrm{H}^{\prime} \mathrm{Q}$ interval of $40 \mathrm{msec}$. The $\mathrm{H}$ and $\mathrm{H}^{\prime}$ have no fixed relation to each other.

Case 2 This 87-year-old white woman was admitted to the hospital with a history of recent dizziness. The patient also had several syncopal episodes two days before the,admission. On examination the pulse rate was 40 a minute and the blood pressure was $124 / 80$ mmHg. A 12-lead electrocardiogram recorded on admission (Fig. 3) showed complete AV block with narrow QRS complexes. A temporary transvenous pacemaker was inserted and His bundle recordings were obtained. Right atrial pacing at increasing rates was performed subsequently.

In Fig. 4 the His bundle electrograms of this patient are shown. Each atrial depolarization (A) is followed by a biphasic spike labelled $\mathrm{H}$ at an $\mathrm{AH}$ interval of $70 \mathrm{msec}$. Every ventricular depolarization is preceded by another biphasic spike labelled $\mathrm{H}^{\prime}$ at an $\mathrm{H}^{\prime} \mathrm{Q}$ interval of $40 \mathrm{msec}$. The $\mathrm{H}$ and $\mathrm{H}^{\prime}$ have no relation to each other. Right atrial pacing at increasing rates increased the $\mathrm{AH}$ interval but complete AV block persisted. His bundle pacing was unsuccessful. Intravenous atropine ( $\mathrm{I} \mathrm{mg}$ ) increased the atrial rate from 85 to I05 a minute, but the ventricular rate remained unchanged.

Case 3 This 85-year-old white man was admitted because of multiple syncopal episodes over a threemonth period. A year before this admission the electrocardiogram had shown 2:I AV block with a QRS pattern of right bundle-branch block. Electrocardiogram on this admission (Fig. 5) showed complete heart block with an atrial rate of 83 a minute and a ventricular rate of 34 a minute. The idioventricular complexes showed a pattern consistent with right bundle-branch block. Intravenous atropine $(2 \mathrm{mg})$ increased the ventricular rate from 34 to 39 a minute. The His bundle electrograms were recorded during the pacemaker insertion. Baseline His bundle electrograms are shown in Panel I of Fig. 6. Each atrial depolarization (A) is followed by an $\mathrm{H}$ at an $\mathrm{AH}$ interval of $90 \mathrm{msec}$. Every ventricular depolarization is preceded by an $\mathrm{H}^{\prime}$ at an $\mathrm{H}^{\prime} \mathrm{Q}$ interval of $45 \mathrm{msec}$. No fixed relation exists between $\mathrm{H}$ and $\mathrm{H}^{\prime}$. The effect of atrial pacing at a rate of 145 a minute is shown in Panel II of Fig. 6. The AH interval has increased to $140 \mathrm{msec}$ and the complete heart block persists.

In Fig. $7 \mathrm{~A}$ and $7 \mathrm{~B}$ the results of His bundle pacing are shown. Pacing was achieved by the catheter that initially recorded the His bundle electrogram. The atrial pacing catheter was used to record the right atrial electrogram (RAE). The His bundle pacing was performed at a fixed rate of 75 a minute. In Fig. $7 \mathrm{~A}$ and $7 \mathrm{~B}$ each $\mathrm{QRS}$ complex is preceded by a pacer impulse (PI) at a PIQ interval of $45 \mathrm{msec}$, which is similar to the $\mathrm{H}^{\prime} \mathrm{Q}$ interval recorded during spontaneous rhythm. In addition, $Q R S$ morphology of the paced beats is similar to the idioventricular complexes. This supports the validity of the His bundle pacing. Two pacer impulses, i.e. last in Fig. 7A and the one before last in Fig. $7 \mathrm{~B}$, are not followed by any ventricular activity (this will be discussed further).

In Fig. $7 \mathrm{~A}$, each of the first three pacer impulsds is followed by a ventricular activity and a retrograde atrial deflection marked rA. This suggests that the pacing catheter is able to pace the His bundle completely so that both antegrade and retrograde conduction could occur. A sinus P comes exactly at the time of the fourth pacer impulse. A QRS follows the fourth pacer impulse at $45 \mathrm{msec}$ interval but there is no retrograde atrial

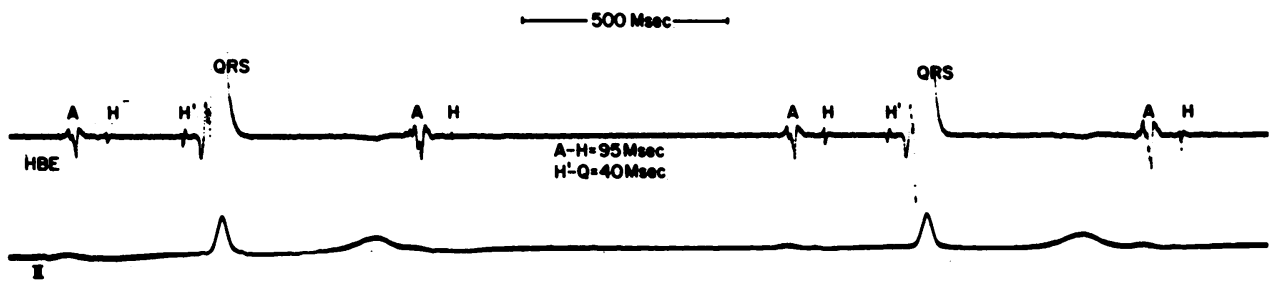

FIG. 2 Case I. His bundle electrograms showing complete heart block with presence of two types of His bundle potentials, i.e. $H$ and $H^{\prime}$. Paper speed $150 \mathrm{~mm} / \mathrm{sec}$. 


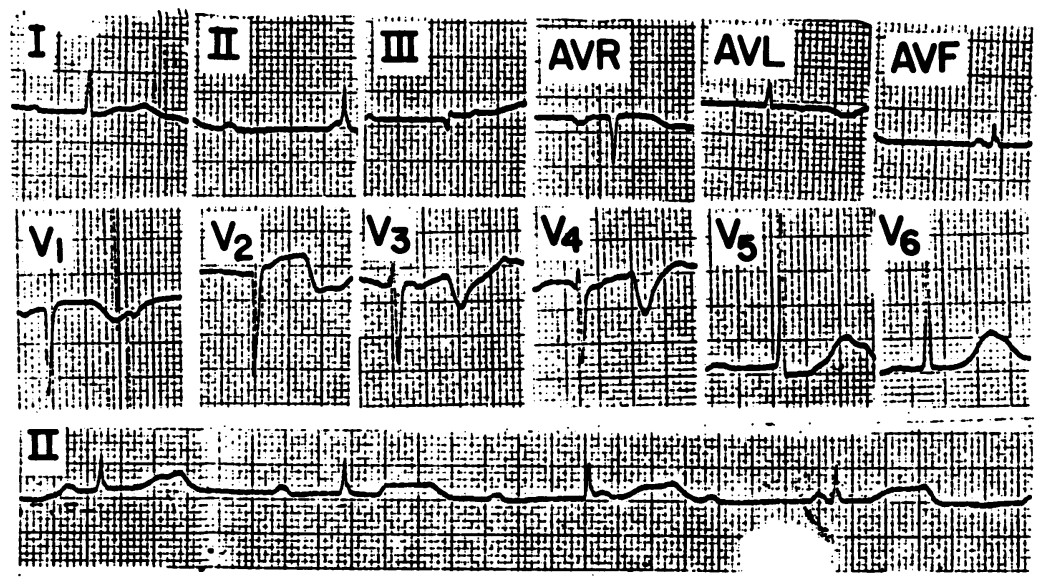

FIG. 3 Case 2. $A$ I2-lead electrocardiogram with rhythm strip showing complete $A V$ block. $Q R S$ complexes are narrow.

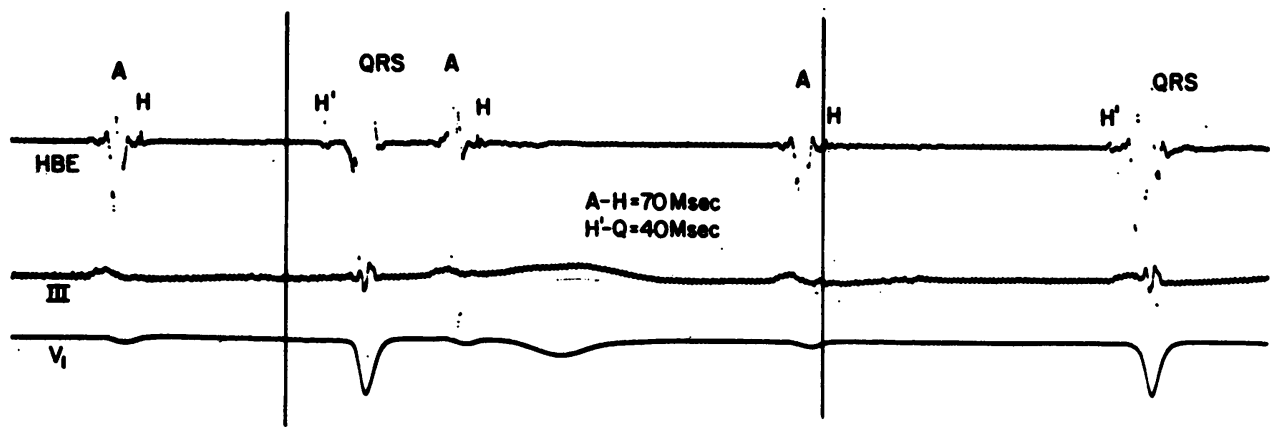

FIG. 4 Case 2. His bundle electrograms showing complete heart block and presence of split His bundle potentials. Paper speed $150 \mathrm{~mm} / \mathrm{sec}$. Time lines I sec apart.

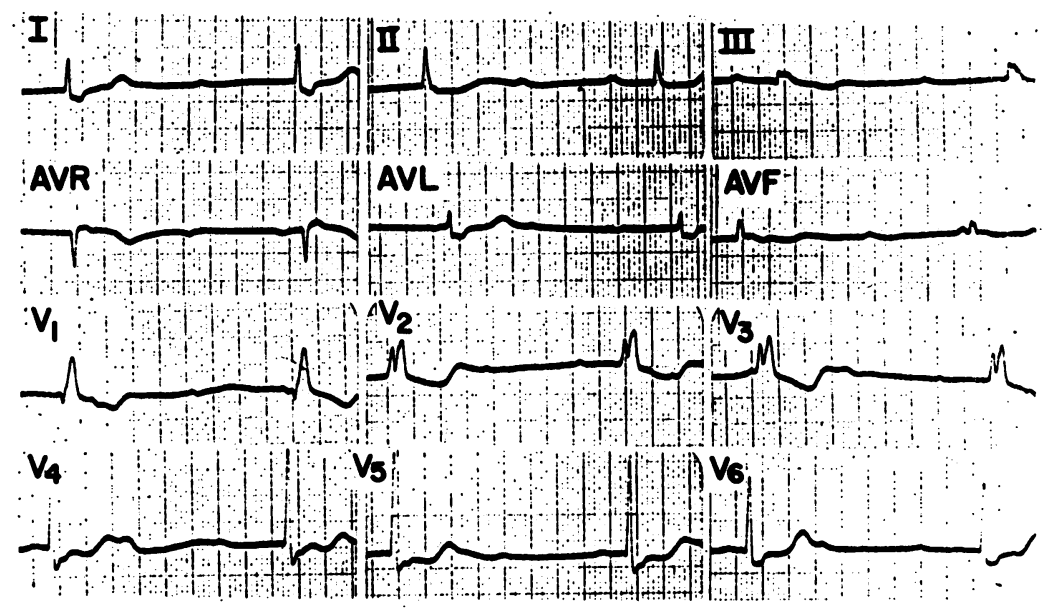

FIG. 5 Case 3. A I2-lead electrocardiogram showing complete heart block. The QRS morphology is consistent with complete right bundle-branch block. 

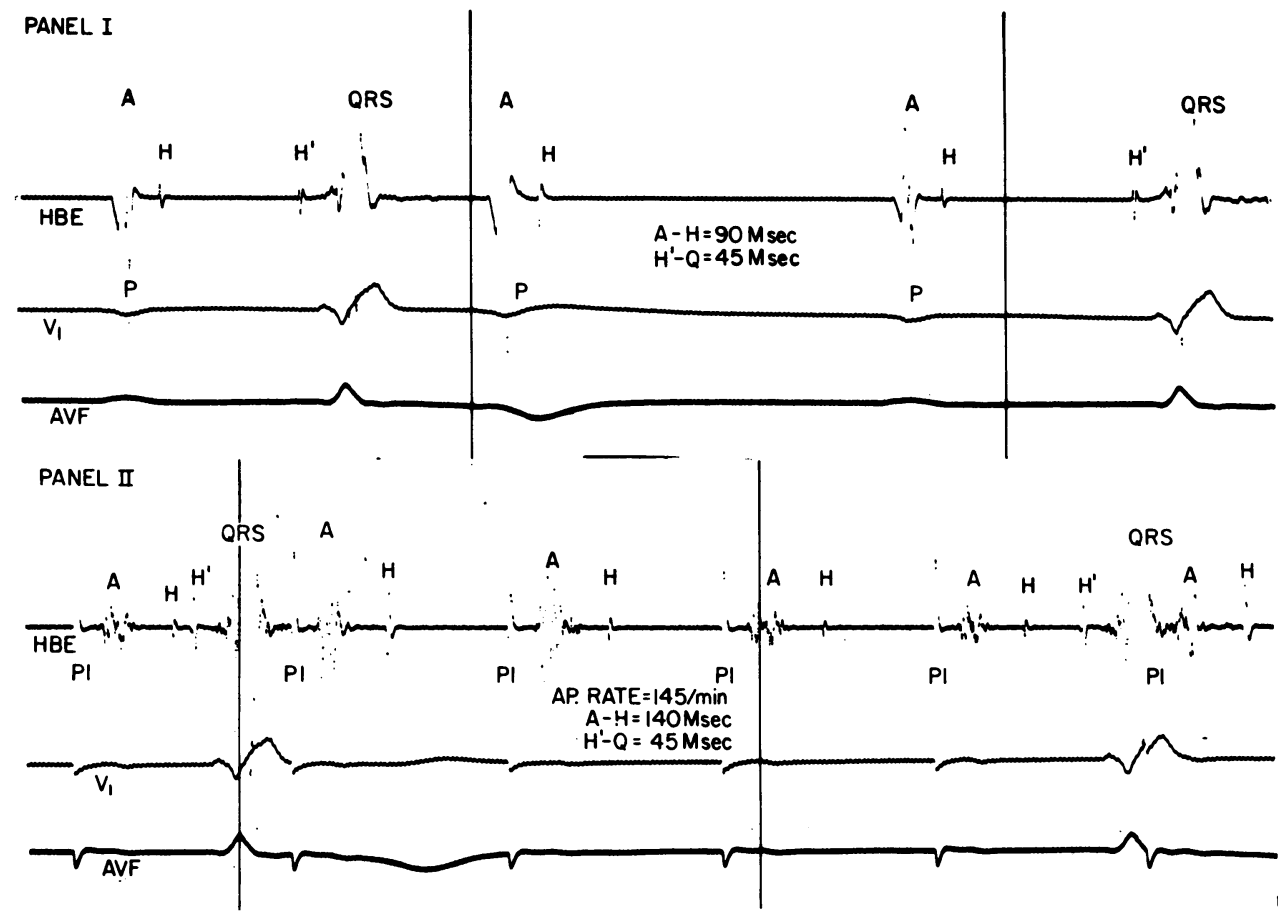

FIG. 6 Case 3. In panel I, baseline His bundle electrograms are shown. Double or split His bundle potentials are seen. In panel II the effect of atrial pacing at a rate of I 45 a minute is shown. Paper speed $150 \mathrm{~mm} / \mathrm{sec}$ and time lines I sec apart.

activity because of the refractoriness of the AV node due to the earlier sinus $P$ wave. The last impulse falls about $90 \mathrm{msec}$ after a sinus $\mathrm{P}$ wave and is not followed by a ventricular depolarization. This is possibly due to the refractoriness of the proximal His bundle segment which was depolarized by the earlier sinus $P$ wave. This finding suggests that in order to achieve His bundle pacing, both segments of the His bundle had to be in a nonrefractory state at the time of the pacer impulse.

In Fig. $7 \mathrm{~B}$, the first three atrial depolarizations are of sinus origin whereas the last four represent retrograde activation of the atria (rA). The first two pacer impulses come at intervals of 230 and $290 \mathrm{msec}$ from the preceding sinus atrial depolarizations. Both pacer impulses are followed by the ventricular activity but no retrograde atrial activity. This suggests that the proximal His bundle segment has recovered from the previous atrial depolarization and is no longer refractory to the pacer impulse, but the AV node is still refractory and hence there is no retrograde conduction to the atria. The third pacer impulse comes $350 \mathrm{msec}$ after the third sinus A and is followed by a ventricular depolarization as well as a retrograde atrial activity. It is clear that the further away the pacer impulse is from a sinus $A$, the better the chance of its being conducted forward and backward. The fifth impulse is followed by an rA, but no ventricular complex. There are two possibilities to explain this beat. It is possible that the fifth pacer impulse instead of depolarizing the whole His bundle, just depolarized the AV node and proximal His bundle segment and hence only the rA could occur. The other possibility is that the fifth pacer impulse, in fact, depolarized the whole of the His bundle and the antegrade conduction showed a Mobitz type II block in the left bundle-branch.

\section{Discussion}

Recent studies using His bundle electrograms have shown the site of block to be distal to the His bundle potential in the majority of patients with chronic complete heart block (Narula et al., 1970a; Steiner et al., 197I). Heart block occurring within the main His bundle was first described by Narula and Samet (1970). They demonstrated the presence of double or split His bundle potentials which signify the electrical activity of the proximal and distal segments of the His bundle. Recently, others have reported cases with various degrees of block within the His bundle (Gupta et al., 1972a; Rosen et al., I97I; Rosen et al., 1972; Schuilenberg and Durrer, 1972). Pathological confirmation of this interesting electrophysiological entity is not available. 


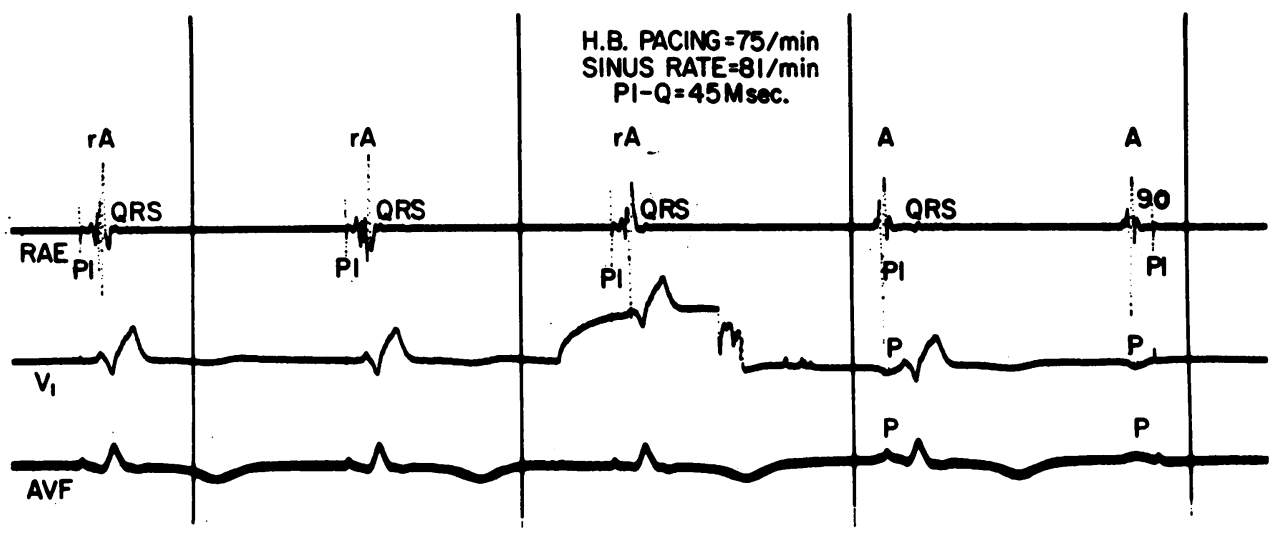

FIG. 7A Case 3. Results of His bundle pacing at a rate of 75 a minute are shown. RAE, right atrial electrogram; PI, pacer impulses; $r A$, retrograde atrial depolarization. For details see text. Paper speed $75 \mathrm{~mm} / \mathrm{sec}$. Time lines I sec apart.

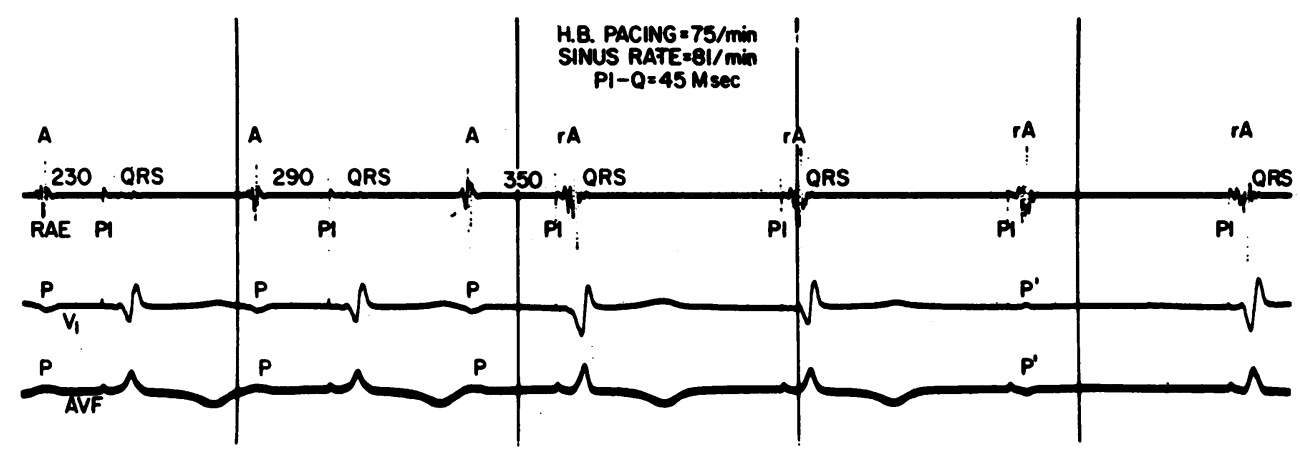

F I G. 7B Case 3. His bundle pacing at a rate of 75 a minute. Sinus rate is 81 a minute. $P^{\prime}$, retrograde $P$ waves. Other abbreviations as in Fig. 7 A. For details see text. Paper speed $75 \mathrm{~mm} / \mathrm{sec}$. Time lines I sec apart.

The 3 cases presented here are among the $2 \mathrm{I}$ cases of chronic complete heart block studied in our laboratory during the past 2 years. We have previously reported 2 patients with Mobitz type II AV block within the His bundle (Gupta, Lichstein, and Chadda, 1972b). Schuilenberg and Durrer (1972) reported 4 cases of block within the His bundle: 2 patients had Mobitz type II AV block while the other 2 had complete heart block. While most of the patients reported appear to have arteriosclerotic or degenerative heart disease, this type of block has also been found with traumatic heart disease (Rosen et al., 1972) and congenital heart disease (Rosen et al., 1971). These data suggest that block within the His bundle may not be as uncommon as previously considered.

Block within the His bundle cannot be distin- guished electrocardiographically from block within the AV node. In either instance, if the block is complete, the QRS morphology is of a supraventricular type, unless a prior bundle-branch block is present (Case 3 in the present report and Case 4 of Schuilenberg and Durrer (1972)). Though we have noted only Mobitz type II patterns in our cases of seconddegree AV block, Wenckebach patterns have also been described (Narula and Samet, 1970).

Atrial pacing at increasing rates progressively increases the AH interval and is one of the methods of His potential validation (Damato et al.,) 1969. His bundle pacing is another method which has been suggested (Narula, Scherlag, and Samet, 1970b), but is not recommended by others (Rosen et al., 1972). In our experience, continuous $\mathrm{His}$ bundle pacing is difficult to achieve and it invariably results in the 
stimulation of the adjacent myocardium. However, if one is successful in pacing the His bundle, this strongly supports the validity of the His bundle potential. A right bundle potential can be separated from the distal His bundle potential by the shorter $\mathrm{RBQ}$ interval and the position of the recording catheter.

Unlike patients with AV nodal block, patients with intra-His block do not increase their ventricular rate adequately after intravenous atropine administration (Narula and Samet, 197I ; Rosen et al., 197I, 1972). This is possibly because of the lack of autonomic control on the distal His bundle segment. In 2 of our patients, where atropine was used, the heart rate either did not increase or increased slightly.

In conclusion, complete AV block within the His bundle can only be localized with the aid of the His bundle electrogram. The electrocardiogram is of little help since the QRS complexes have a supraventricular morphology. Atropine usually does not increase the heart rate.

Miss Nancy McNamara, R.N., assisted during the procedures.

\section{References}

Damato, A. N., Lau, S. H., Helfant, R. H., Stein, E., Berkowitz, W. D., and Cohen, S. I. (1969). Study of atrioventricular conduction in man using electrode catheter recordings of His bundle activity. Circulation, 39, 287.

Gupta, P., Chadda, K., Lichstein, E., Liu, H., and Sayeed, M. (1972a). His bundle lesions producing heart block electrophysiological documentation. Clinical Research, 20, 375 .

Gupta, P. K., Lichstein, E., and Chadda, K. D. (1972b). Electrophysiological features of Mobitz type II block occurring within the His bundle. British Heart fournal, 34, 1232.

Narula, O. S., and Samet, P. (1970). Wenckebach and Mobitz type II A-V block due to block within the His bundle and bundle branches. Circulation, 41, 947.

Narula, O. S., and Samet, P. (197I). Effect of atropine and glucagon on $\mathrm{A}-\mathrm{V}$ nodal and His bundle pacemakers in man (abstract). Circulation, 44, Suppl. II, 205.

Narula, O. S., Scherlag, B. J., Javier, R. P., Hildner, F. J., and Samet, P. (1970a). Analysis of the A-V conduction defect in complete heart block utilizing His bundle electrograms. Circulation, 41, 437.

Narula, O. S., Scherlag, B. J., and Samet, P. (I970b). Pervenous pacing of the specialized conducting system in man. His bundle and A-V nodal stimulation. Circulation, 4I, 77.

Rosen, K. M., Heller, R., Ehsani, A., and Rahimtoola, S. H. (1972). Localization of site of traumatic heart block with His bundle recordings. American fournal of Cardiology, 30, 412.

Rosen, K. M., Mehta, A., Rahimtoola, S. H., and Miller, R. A. (1971). Sites of congenital and surgical heart block as defined by His bundle electrography. Circulation, 44, 833 .

Scherlag, B. J., Lau, S. H., Helfant, R. H., Berkowitz, W. D., Stein, E., and Damato, A. N. (1969). Catheter technique for recording His bundle activity in man. Circulation, 39, 13.

Schuilenberg, R. M., and Durrer, D. (1972). Conduction disturbances located within the His bundle. Circulation, 45, 612.

Steiner, C., Lau, S. H., Stein, E., Wit, A. L., Weiss, M. B., Damato, A. N., Haft, J. I., Weinstock, M., and Gupta, P. (1971). Electrophysiologic documentation of trifascicular block as the common cause of complete heart block. American fournal of Cardiology, 28, 436.

\section{Addendum}

Since completion of this manuscript we have seen another patient with complete AV block within the His bundle. This patient had previously shown Mobitz type II block within the His bundle (Gupta et al., 1972b).

Requests for reprints to Dr. Prem K. Gupta, Division of Cardiology, Mount Sinai Hospital Services, City Hospital Center at Elmhurst, 79-Or Broadway, Elmhurst, New York II373, U.S.A. 